such a roan as might be mistaken for a red unless closely examined.

Here, then, is one of our most distinguished breeders referring to substitution, and making an error of description as regards the colour of a calf.

The last time I visited the farm where the above " red" bull is standing I saw some white calves, and this afternoon one of them, now six or eight weeks old, was missing. I asked the owner what had become of him, and got the reply, "I have sold him." This particular white calf may be referred to in the Herd-book by his breeder, but many another similar one is never referred to at all.

Prof. Pearson suggests that, if there are inaccuracies and misstatements in the Herd-book, "Mendelism cannot be discussed on the basis of the Shorthorn data." I do not agree. But, if not Mendelism, can biometric theories be discussed upon the same data?

The latter half of Prof. Pearson's letter does not bear much upon the present issue, but I should not be astonished, if his theories as to colour determinants and parti-colours are followed up, that each of the two races from which the Shorthorn is descended should split up into more than one variety.

Prof. Pearson thinks that, because I neglected the figures in the first part of his original paper, I was evading some of the data. This is not so. I did not notice that they comprised other data, for which I am sorry, because the ninety-one white crossings which gave eighty-six white calves, four roans, and one red, would have been helpful. I had not seen the original paper since the time it was published two years ago, and, when I conceived the idea that Shorthorns are Mendelians, I went straight to the two tables from which I quoted, in the belief that they contained all the relevant data collected by Miss Barrington and Prof. Pearson.

Royal College of Science. Dublin, April 8.

\section{The Nature of $\gamma$ and X-Rays.}

IF I am putting the correct interpretation on $\mathrm{Mr}$. Barkla's letter in NATURE of February 6 (p. 319), I have to thank him for the admission that his experiments are not so contrary to the neutral pair theory as he had at first supposed.

Mr. Barkla still concludes, however, in favour of the ether pulse theory. He has compared the intensities of two secondary beams emitted by carbon under the influence of an unpolarised primary beam, the one returning on the track of the incident rays, the other moving in a perpendicular direction. His calculated ratio is $2: 1$ i experiment gives I.85 to I (Phil. Mag., February, p. 293). Such an agreement has its value. But, at the same time, he finds that for harder rays the ratio drops to $\mathrm{I} .45$ to $\mathrm{X}$, with no sign of a limit. His theory is unable to predict this decline, far less to measure its amount. It is no compliment to the ether pulse theory to describe such incomplete successes as " absolutely conclusive evidence."

He invites me to suggest a theory of scattering which shall have as much success as his own. But, on the neutral pair theory, the laws of scattering must depend directly on the constitution of the atom, as to which it is scarcelv possible to do more than speculate. It is not incumbent on me at this stage to frame an independent hypothesis by the success of which my older one is to be juidged.

$\mathrm{He}$ wishes to avoid arguments founded on an experimental study of the $\gamma$ rays. But it is quite legitimate to begin with the $\gamma$ rays, and to carry the argument over to the X-rays, on the ground that there is an extremely close parallelism between the two types. Evidence of this sort cannot be avoided by resolutely facing the other way.

It will perhaps conduce to greater clearness if I state my position briefly.

(I) Nearly a year ago I pointed out that almost all the phenomena of $\gamma$ and X-rays could be explained on a neutral pair theory at least as well as on an ether pulse theory. This applied particularly to all effects connected with the production of secondary kathode rays of high velocity, effects which are at the root of most of what has been observed.

NO. 2007, YOL. 7 ]
(2) I have recently described some experiments carried out by Dr. Madsen and myself which seem to me to support my contention in the strongest way as regards the $\gamma$ rays.

(3) Since $\mathrm{X}$-rays and $\gamma$ rays resemble each other so faithfully in most respects, particularly those connected with the high-speed kathode rays, I have therefore suggested that the experiments also support my contention regarding the nature of the bulk of the X-rays.

(4) There are a few outstanding phenomena of the X-rays which do not fit in so readily with a neutral pair hypothesis, particularly Marx's velocity experiment, and the diffraction experiments of Haga and Windt. These seem to prove the existence and activity of ether pulses. As regards Mr. Barkla's polarisation effects, I have indicated a possible way of explaining them on the neutral pair theory; but I am quite content to wait for the guidance of future experiments, amongst which Mr. Barkla's recent work will take its proper place.

(5) If I admit the existence of ether pulses, I do not thercby weaken my contention that the most important and effective part of $\gamma$ and $\mathrm{X}$-ray radiation is material. We know that ether pulses exist; it does not follow that they do everything. On the contrary, the evidence for the ether pulse theory is extremely weak in just this direction; there is a danger that the post hoc has been confused with the propter hoc. When I see a boy jerk his arm, and hear immediately afterwards a rattling on my roof, I know quite well that the motion of the boy's arm has set an air pulse going, but I do not conclude that one of my chimneys was in a dangerously explosive condition, and that the air pulse has precipitated the violent discharge of half a brick.

The University of Adelaide, South Australia, March 12.

\section{The Corrosion of Iron and Steel.}

A PAPER describing the investigation of the causes of rusting of iron was read in May, I907, before the New York Section of the American Chemical Society by $\mathrm{Mr}$. William $H$. Walker and others, and has been recently printed in this country. After criticising the various explanations which have been put forward of the rusting of iron in contact with water, the authors approve the suggestion of Whitney that the first step in the process is the escape into the liquid of iron in the form of positively charged ions. In confirmation of this, the authors state that they succeeded in detecting iron by chemical tests in water which contained only a trace of electrolyte, and was free from oxygen and carbon dioxide, after the water had been in contact with iron.

Such an explanation would apply to a fact which confronted me some years since when investigating the cause of the action of water on lead. Every precaution was adopted to bring a surface of metallic lead absolutely free from oxide into contact with water free from dissolved gases, with the expectation that if these conditions were fully complied with no lead would pass into solutiòn. In the course of the investigation the precautions which were taken to secure the conditions specified gradually became more stringent, and the amount of lead passing into solution was correspondingly reduced; but when the utmost possible care had been taken, lead in very minute proportion was still detectable in the water by chemical tests. It is of interest to note that the proportion of lead was constant when the contact of water with lead had been brought about in repeated experiments with some variations in detail. The impression produced by these results on my own mind was that undoubtedly lead in the metallic state must have passed into the water, and upon reconsideration of the experimental work and its results I feel satisfied that this was the case, and that the lead probably passed into the water as iron did in the experiments made by Whitney and repeated by the American investigators, when they brought iron into contact with water under conditions similar to those which I had secured.

The Grange, Dulwich.

Frank Clowes. 